\title{
The Short-Term Cost-Effectiveness of Once-Weekly Semaglutide Versus Once-Daily Sitagliptin and Once- Weekly Dulaglutide for the Treatment of Patients with Type 2 Diabetes: A Cost of Control Analysis in Spain
}

\author{
Josep Vidal - Samuel J. P. Malkin · Barnaby Hunt (1) - Virginia Martín · \\ Nino Hallén · Francisco Javier Ortega
}

Received: November 15, 2019 / Published online: January 10, 2020

(C) The Author(s) 2020

\begin{abstract}
Introduction: Once-weekly semaglutide has been associated with greater reductions in glycated hemoglobin (HbA1c) and body weight than sitagliptin and dulaglutide in the SUSTAIN 2 and 7 clinical trials, respectively. These trials also assessed the proportions of patients achieving treatment targets capturing glycemic control and avoidance of hypoglycemia
\end{abstract}

Enhanced Digital Features To view enhanced digital features for this article go to https://doi.org/10.6084/ m9.figshare.11359718.

J. Vidal

Endocrinology and Nutrition Department, Hospital Clínic, Barcelona, Spain

J. Vidal

Centro de Investigación Biomédica en Red en Diabetes y Enfermedades Metabólicas Asociadas (CIBERDEM), Barcelona, Spain

S. J. P. Malkin · B. Hunt ( $\square)$

Ossian Health Economics and Communications, Basel, Switzerland

e-mail: hunt@ossianconsulting.com

V. Martín

Novo Nordisk Pharma SA, Madrid, Spain

N. Hallén

Novo Nordisk A/S, Søborg, Denmark

F. Javier Ortega

Campos-Lampreana Primary Healthcare Centre,

Zamora, Spain and weight gain. This study assessed the cost of bringing patients with type 2 diabetes to three clinically relevant endpoints with semaglutide versus sitagliptin and dulaglutide in Spain.

Methods: The proportions of patients achieving endpoints of $\mathrm{HbA} 1 \mathrm{c}<7.0 \%, \mathrm{HbA} 1 \mathrm{c}<7.0 \%$ without hypoglycemia and without weight gain, and $\mathrm{a} \geq 1.0 \% \mathrm{HbA1c}$ reduction with $\geq 5.0 \%$ weight loss were taken from SUSTAIN 2 and 7. Cost of control was calculated as the annual per patient cost of each medication, expressed in 2019 euros (EUR), divided by the proportion of patients achieving each endpoint. Results: Based on SUSTAIN 2, cost of control was lower for sitagliptin for the HbA1c $<7.0 \%$ endpoint, results were comparable for the HbA1c $<7.0 \%$ without hypoglycemia and without weight gain endpoint, and both doses of semaglutide were associated with lower costs of control for the $\geq 1.0 \% \mathrm{HbA} 1 \mathrm{c}$ reduction with $\geq 5.0 \%$ weight loss endpoint. Based on SUSTAIN 7, both doses of semaglutide were associated with lower costs of control for all three endpoints.

Conclusion: Both doses of semaglutide were associated with comparable or lower costs of control versus sitagliptin when considering endpoints incorporating hypoglycemia and weight loss alongside glycemic control, and lower costs of control versus dulaglutide $1.5 \mathrm{mg}$ for all endpoints in Spain.

Plain Language Summary: Plain language summary available for this article. 
Keywords: Cost; Cost-effectiveness; Cost of control; Diabetes mellitus; Dulaglutide; GLP-1 receptor agonist; GLP-1 analogue; Semaglutide; Sitagliptin; Spain

\section{Key Summary Points}

\section{Why carry out this study?}

Optimizing care for patients with type 2 diabetes by achieving glycemic control targets, preventing weight gain, and avoiding hypoglycemic events can be achieved by using modern interventions, such as glucagon-like peptide 1 (GLP-1) receptor agonists and dipeptidyl peptidase 4 (DPP4) inhibitors

Choosing interventions that can achieve these aims in a cost-effective manner is key for healthcare payers as the prevalence of type 2 diabetes continues to rise

The aim of the present study was to assess the short-term cost of control of bringing patients with type 2 diabetes to clinically relevant endpoints of glycated hemoglobin (HbA1c) $<7.0 \%$, HbA1c $<7.0 \%$ without hypoglycemia and without weight gain, and $\geq 1.0 \% \mathrm{HbA1c}$ reduction with $\geq 5.0 \%$ weight loss with semaglutide $0.5 \mathrm{mg}$, semaglutide $1 \mathrm{mg}$, sitagliptin and dulaglutide in the Spanish setting based on the SUSTAIN 2 and SUSTAIN 7 randomized controlled trials

\section{What was learned from this study?}

Annual costs of control were marginally higher for semaglutide $0.5 \mathrm{mg}$ and $1 \mathrm{mg}$ versus sitagliptin for the endpoints of HbA1c $<7.0 \%$ and HbA1c $<7.0 \%$ without hypoglycemia and without weight gain, but substantially lower for the endpoint of $\mathrm{a} \geq 1.0 \%$ reduction in $\mathrm{HbA} 1 \mathrm{c}$ with $\geq 5.0 \%$ weight loss

Both doses of semaglutide were associated with lower costs of control for all endpoints versus dulaglutide

\section{PLAIN LANGUAGE SUMMARY}

Optimizing care for patients with type 2 diabetes by achieving glycemic control targets, preventing weight gain, and avoiding hypoglycemic events can be achieved by using modern interventions, such as GLP-1 receptor agonists and DPP4 inhibitors. Choosing interventions that can achieve these aims in a costeffective manner is key for healthcare payers as the prevalence of type 2 diabetes continues to rise. The aim of the present study was to assess the short-term cost of control of bringing patients with type 2 diabetes to three clinically relevant endpoints with semaglutide $0.5 \mathrm{mg}$, semaglutide $1 \mathrm{mg}$, sitagliptin and dulaglutide in the Spanish setting based on the SUSTAIN 2 and SUSTAIN 7 randomized controlled trials.

The proportions of patients achieving endpoints of $\mathrm{HbA} 1 \mathrm{c}<7.0 \%$, HbA1c $<7.0 \%$ without hypoglycemia and without weight gain, and a $\geq 1.0 \%$ HbA1c reduction with $\geq 5.0 \%$ weight loss were taken from SUSTAIN 2 and 7. Cost of control was calculated as the annual per patient cost of each medication divided by the proportion of patients achieving each endpoint.

Based on SUSTAIN 2, cost of control was lower for sitagliptin for the HbA1c $<7.0 \%$ endpoint, results were comparable for the HbA1c < $7.0 \%$ without hypoglycemia and without weight gain endpoint, and both doses of semaglutide were associated with lower costs of control for the $\geq 1.0 \% \mathrm{HbA} 1 \mathrm{c}$ reduction with $\geq 5.0 \%$ weight loss endpoint. Based on SUSTAIN 7, both doses of semaglutide were associated with lower costs of control for all three endpoints.

\section{INTRODUCTION}

Direct healthcare expenditure for type 2 diabetes in Spain exceeded EUR 9 billion in 2017 [1-3]. As healthcare payers are faced with increasingly limited budgets, choosing therapies that are cost-effective is becoming crucial. While it is well established that the majority of costs associated with diabetes are from longterm complications, economic constrains mean 
that healthcare payers often set budgets where larger weight is given to short-term costs, such as medication acquisition costs.

A key treatment target for type 2 diabetes remains a glycated hemoglobin (HbA1c) of less than $7.0 \%$, but latest guidelines recommend more individualized targets $[4,5]$. Importantly, reductions in $\mathrm{HbA} 1 \mathrm{c}>0.9 \%$ have been associated with a reduced risk of microvascular complications. Furthermore, reductions in body weight have been associated with a reduced incidence of long-term complications, as well as short-term improvements in patients' quality of life [6-12]. Additional parameters such as avoidance of hypoglycemia or weight gain are therefore currently considered as relevant outcomes of diabetes therapies in both Spainspecific and Europe-wide guidance [4, 5].

Incretin therapies, including glucagon-like peptide 1 (GLP-1) receptor agonists and dipeptidyl peptidase 4 (DPP4) inhibitors, represent modern treatments for type 2 diabetes that offer multifactorial benefits. The DPP4 inhibitor sitagliptin has been associated with improved glycemic control in patients with type 2 diabetes, while displaying weight neutrality and a low risk of hypoglycemia alongside good tolerability [5, 13]. GLP-1 receptor agonists have been associated with reductions in body weight and systolic blood pressure in addition to improved glycemic control, while displaying a low hypoglycemia risk [14-17]. Among GLP-1 receptor agonists, semaglutide has consistently displayed the greatest short-term efficacy, with greater reductions in $\mathrm{HbA1c}$ and body weight versus a variety of comparators (including DPP4 inhibitor sitagliptin and GLP-1 receptor agonist dulaglutide) throughout the SUSTAIN clinical trial program and several network meta-analyses (NMAs) [18-23]. In patients without established cardiovascular or chronic kidney disease, European Association for the Study of Diabetes (EASD) guidelines indicate that DPP4 inhibitors, GLP-1 receptor agonists or sodium/glucose cotransporter 2 (SGLT2) inhibitors as a secondline therapy following metformin failure where there is a compelling need to minimize hypoglycemia [5]. In patients with established cardiovascular disease, certain GLP-1 receptor agonists have been associated with a reduced risk of major cardiovascular events (MACE), with semaglutide, liraglutide, and dulaglutide displaying the most favorable profiles in SUSTAIN 6, LEADER, and REWIND, respectively [24-26]. Sitagliptin, conversely, has only been associated with no significant increase in the risk of MACE in TECOS [27]. Considering results from these trials, EASD guidelines specifically recommend GLP-1 receptor agonists as the firstline injectable therapy in patients with a high risk of cardiovascular events or seeking to minimize weight gain [5]. In the latter case, semaglutide could be viewed as the preferred treatment option with the best efficacy for weight loss alongside a reduced risk of cardiovascular disease.

In addition to the primary outcome measure of change in HbA1c in the SUSTAIN clinical trial program, these trials also assessed the proportions of patients achieving clinically relevant single and composite endpoints. Previous cost of control analyses for semaglutide have assessed the cost of bringing patients to these endpoints in the US, but to date no such studies have been published for the Spanish setting [28]. From the medications assessed in the SUSTAIN clinical trials, sitagliptin and dulaglutide represent the most relevant comparators for semaglutide for the treatment of type 2 diabetes in Spain.

The aim of the present study was to provide relevant information for healthcare payers interested in treatments that target reductions in HbA1c while avoiding hypoglycemia and weight gain, through the assessment of the short-term costs of bringing patients with type 2 diabetes to three clinically relevant endpoints with semaglutide, sitagliptin, and dulaglutide in the Spanish setting.

\section{METHODS}

\section{Modeling Approach}

Short-term cost-effectiveness was assessed in terms of the cost per patient achieving each endpoint (cost of control), using a bespoke model built in Microsoft Excel (Microsoft Corporation, Redmond, WA) [28]. Four 
interventions were evaluated: subcutaneous injectable once-weekly semaglutide $0.5 \mathrm{mg}$ and $1 \mathrm{mg}$, orally administered once-daily sitagliptin $100 \mathrm{mg}$, and subcutaneous injectable onceweekly dulaglutide $1.5 \mathrm{mg}$. While the lower $0.75 \mathrm{mg}$ dose of dulaglutide was also assessed in SUSTAIN 7, this is indicated only for monotherapy or in patients aged greater than 75 years by the European Medicines Agency (EMA), so this dose was not included in the present study [29]. Cost of control was calculated for three endpoints: HbA1c $<7.0 \%$, HbA1c $<7.0 \%$ without hypoglycemia and without weight gain, and $\mathrm{a} \geq 1.0 \% \mathrm{HbA1c}$ reduction with $\geq 5.0 \%$ weight loss. This approach allows the short-term cost-effectiveness of interventions to be evaluated in a simple, transparent, and clinically relevant manner. Analyses were performed over a 1-year time horizon, with no discounting applied.

The numbers of patients needed to treat to bring one patient to each of the three targets were calculated as the reciprocals of the proportions of patients achieving each target. Absolute cost of control was calculated by dividing the annual treatment cost of each medication by the proportions of patients achieving each target, while relative cost of control was calculated relative to semaglutide $1 \mathrm{mg}$, by dividing the absolute cost of control values for semaglutide $0.5 \mathrm{mg}$, sitagliptin, and dulaglutide by the value calculated for semaglutide $1 \mathrm{mg}$. The intervention with the lowest cost of control for a given endpoint can be considered the most cost-effective treatment option.

\section{Clinical Data}

Clinical data, in terms of the proportions of patients reaching each of the three endpoints included in the present analysis, were taken from the SUSTAIN 2 and SUSTAIN 7 clinical trials, for comparisons with sitagliptin and dulaglutide, respectively (Table 1) [18, 21, 30]. SUSTAIN 2 was a 56 -week, randomized, doubleblinded trial comparing semaglutide $0.5 \mathrm{mg}$ and $1 \mathrm{mg}$ with once-daily sitagliptin $100 \mathrm{mg}$ in people with type 2 diabetes uncontrolled on metformin, pioglitazone, rosiglitazone, or combinations of either metformin and pioglitazone or metformin and rosiglitazone [18]. Concomitant medication use at baseline did not differ between the treatment arms, with $99.1 \%$ of participants receiving metformin and $5.1 \%$ of patients receiving a thiazolidinedione. SUSTAIN 7 was a 40-week, randomized, doubleblinded trial comparing semaglutide $0.5 \mathrm{mg}$ and $1 \mathrm{mg}$ with once-weekly dulaglutide $0.75 \mathrm{mg}$ and $1.5 \mathrm{mg}$ in people with type 2 diabetes uncontrolled on metformin $(100 \%$ of patients were receiving metformin with no patient receiving other concomitant diabetes medications at baseline) [21]. The proportions of patients achieving each endpoint were taken from the end of each trial. HbA1c was defined in percentage terms based on the National Glycohemoglobin Standardization Program approach. An $\mathrm{HbA} 1 \mathrm{c}$ of $7 \%$ is equivalent to $53 \mathrm{mmol} / \mathrm{mol}$, while a change in $\mathrm{HbA} 1 \mathrm{c}$ of $1 \%$ is equivalent to a change of $10.9 \mathrm{mmol} / \mathrm{mol}$. Hypoglycemia was defined as severe or blood glucose confirmed events, with a severe event defined based on the American Diabetes Association criteria of an episode requiring assistance of another person to actively administer carbohydrate, glucagon, or take other corrective actions, while a blood glucose confirmed event was defined as a plasma glucose measurement $<3.1 \mathrm{mmol} / \mathrm{L}$ $(56 \mathrm{mg} / \mathrm{dL})$ with symptoms consistent with hypoglycemia.

\section{Cost Data and Resource Use}

Analyses were conducted from the perspective of a healthcare payer in Spain and costs were expressed in 2019 euros (EUR) [31]. Only medication acquisition costs were included, as sitagliptin is administered orally and needles are included in the semaglutide and dulaglutide packs (Table 2). It was assumed that patients would not require any self-monitoring of blood glucose (SMBG) testing, as the low levels of hypoglycemia associated with the included interventions were not expected to impact cost outcomes [18, 21].

The annual cost of treatment with semaglutide $0.5 \mathrm{mg}$ or $1 \mathrm{mg}$ was estimated to be 
Table 1 Proportions of patients achieving endpoints in SUSTAIN 2 and SUSTAIN 7

\begin{tabular}{|c|c|c|c|c|}
\hline Endpoint & $\begin{array}{l}\text { Semaglutide } \\
0.5 \mathrm{mg}\end{array}$ & $\begin{array}{l}\text { Semaglutide } \\
1 \mathrm{mg}\end{array}$ & $\begin{array}{l}\text { Sitagliptin } \\
100 \mathrm{mg}\end{array}$ & $\begin{array}{l}\text { Dulaglutide } \\
1.5 \mathrm{mg}\end{array}$ \\
\hline \multicolumn{5}{|l|}{ SUSTAIN 2, mean (standard error) } \\
\hline HbAlc $<7.0 \%$ & $69 \%(2.3 \%)$ & $78 \%(2.0 \%)$ & $36 \%(2.4 \%)$ & - \\
\hline $\begin{array}{l}\text { HbAlc }<7.0 \% \text { without hypoglycemia and } \\
\text { without weight gain }\end{array}$ & $63 \%(2.4 \%)$ & $74 \%(2.2 \%)$ & $27 \%(2.2 \%)$ & - \\
\hline $\begin{array}{l}\geq 1.0 \% \mathrm{HbA} 1 \mathrm{c} \text { reduction with } \geq 5.0 \% \text { weight } \\
\text { loss }\end{array}$ & $35 \%(2.4 \%)$ & $54 \%(2.1 \%)$ & $9 \%(0.8 \%)$ & - \\
\hline \multicolumn{5}{|l|}{ SUSTAIN 7, mean (standard error) } \\
\hline $\mathrm{HbA} 1 \mathrm{c}<7.0 \%$ & $68 \%(2.7 \%)$ & $79 \%(2.4 \%)$ & - & $67 \%(2.7 \%)$ \\
\hline $\begin{array}{l}\text { HbAlc }<7.0 \% \text { without hypoglycemia and } \\
\text { without weight gain }\end{array}$ & $64 \%(2.8 \%)$ & $74 \%(2.5 \%)$ & - & $58 \%(2.9 \%)$ \\
\hline $\begin{array}{l}\geq 1.0 \% \mathrm{HbA} 1 \mathrm{c} \text { reduction with } \geq 5.0 \% \text { weight } \\
\text { loss }\end{array}$ & $38 \%(2.8 \%)$ & $59 \%(2.6 \%)$ & - & $23 \%(2.4 \%)$ \\
\hline \multicolumn{5}{|c|}{$\begin{array}{l}\text { HbA1c glycated hemoglobin, SUSTAIN } 2 \text { semaglutide } 0.5 \mathrm{mg} n=409 \text {, semaglutide } 1 \mathrm{mg} n=409, \text { sitagliptin } n=407, \\
\text { SUSTAIN } 7 \text { semaglutide } 0.5 \mathrm{mg} n=301 \text {, semaglutide } 1 \mathrm{mg} n=300 \text {, dulaglutide } 1.5 \mathrm{mg} n=299\end{array}$} \\
\hline Medication & (mg) & \multicolumn{2}{|c|}{ Pack price (EUR) } & Reference \\
\hline Semaglutide $0.5 \mathrm{mg}$ & & \multicolumn{2}{|l|}{86.28} & {$[31]$} \\
\hline Semaglutide $1 \mathrm{mg}$ & & \multicolumn{2}{|l|}{86.28} & \\
\hline Sitagliptin $100 \mathrm{mg}$ & & \multicolumn{2}{|l|}{30.83} & \\
\hline Dulaglutide $1.5 \mathrm{mg}$ & & 86.28 & & \\
\hline
\end{tabular}

EUR 2019 euros, $S M B G$ self-monitoring of blood glucose

EUR 1126, versus EUR 402 for sitagliptin and EUR 1126 for dulaglutide $1.5 \mathrm{mg}$. Sitagliptin was therefore estimated to be $36 \%$ as costly as semaglutide, while dulaglutide and semaglutide were associated with equivalent costs.

\section{Sensitivity Analyses}

Sensitivity analyses were conducted around the clinical inputs, which increased and decreased the proportions of patients achieving targets by one standard error, to examine the impact of changes in the input parameters on the results. Additionally, a probabilistic sensitivity analysis
(PSA) was conducted. In this PSA, the proportion of patients achieving each target with each intervention was sampled, and the cost of control calculated. This process was repeated 1000 times, with the mean cost of control for each endpoint with each intervention calculated across all 1000 iterations, as results were stable at this number of iterations.

\section{Compliance with Ethics Guidelines}

This article is based on previously conducted studies and does not contain any studies with 
human participants or animals performed by any of the authors.

\section{RESULTS}

\section{Base Case Analysis}

\section{Number Needed to Treat}

Based on SUSTAIN 2, the numbers of patients needed to treat to bring one patient to target were lowest for semaglutide compared with sitagliptin across all three endpoints (Table 3 ). For HbA1c $<7.0 \%, 1.45,1.28$, and 2.78 patients would need to be treated with semaglutide $0.5 \mathrm{mg}$, semaglutide $1 \mathrm{mg}$, and sitagliptin, respectively, for one patient to achieve target, while approximately $1.59,1.35$, and 3.70 patients would need to be treated with semaglutide $0.5 \mathrm{mg}$, semaglutide $1 \mathrm{mg}$, and sitagliptin, respectively, for one patient to achieve a target of HbA1c $<7.0 \%$ without hypoglycemia and without weight gain. For a $\geq 1.0 \%$ reduction in $\mathrm{HbA} 1 \mathrm{c}$ with $\geq 5.0 \%$ weight loss, $2.86,1.85$, and 11.11 patients would need to be treated with semaglutide $0.5 \mathrm{mg}$, semaglutide $1 \mathrm{mg}$, and sitagliptin, respectively, for one patient to achieve target.

Based on SUSTAIN 7, the numbers of patients needed to treat to bring one patient to target were lowest for semaglutide compared with dulaglutide across all three endpoints (Table 3). For HbA1c $<7.0 \%, 1.47,1.27$, and 1.49 patients would need to be treated with semaglutide $0.5 \mathrm{mg}$, semaglutide $1 \mathrm{mg}$, and dulaglutide $1.5 \mathrm{mg}$, respectively, for one patient to achieve target. For HbA1c $<7.0 \%$ without hypoglycemia and without weight gain, 1.56, 1.35 , and 1.72 patients would need to be treated with semaglutide $0.5 \mathrm{mg}$, semaglutide $1 \mathrm{mg}$, and dulaglutide $1.5 \mathrm{mg}$, respectively, for one patient to achieve target, while for a $\geq 1.0 \%$ reduction in HbA1c with $\geq 5.0 \%$ weight loss, $2.63,1.69$, and 4.35 patients would need to be treated with semaglutide $0.5 \mathrm{mg}$, semaglutide $1 \mathrm{mg}$, and dulaglutide $1.5 \mathrm{mg}$, respectively, for one patient to achieve target.

\section{Cost of Control}

Based on SUSTAIN 2, annual costs of control were marginally higher for semaglutide $0.5 \mathrm{mg}$ and $1 \mathrm{mg}$ versus sitagliptin for the endpoints of HbA1c $<7.0 \%$ (EUR 1631, EUR 1443, and EUR 1117, respectively) and HbA1c $<7.0 \%$ without hypoglycemia and without weight gain (EUR 1787, EUR 1521, and EUR 1490, respectively), but substantially lower for the endpoint of $\mathrm{a} \geq 1.0 \%$ reduction in $\mathrm{HbA} 1 \mathrm{c}$ with $\geq 5.0 \%$ weight loss (EUR 3216, EUR 2084, and EUR 4469, respectively) (Fig. 1). Relative cost of control analysis showed that sitagliptin was associated with a better efficacy-to-cost ratio for endpoints of $\mathrm{HbA} 1 \mathrm{c}<7.0 \%$ and $\mathrm{HbA} 1 \mathrm{c}<7.0 \%$ without hypoglycemia and without weight gain, but semaglutide $0.5 \mathrm{mg}$ and $1 \mathrm{mg}$ were associated with better efficacy-to-cost ratios for the endpoint of $\geq 1.0 \%$ reduction in $\mathrm{HbA} 1 \mathrm{c}$ with $\geq 5.0 \%$ weight loss (Table 3 ).

Based on SUSTAIN 7, both doses of semaglutide were associated with lower costs of control for all endpoints versus dulaglutide (Fig. 1). For the single endpoint of $\mathrm{HbA1c}$ $<7.0 \%$, costs of control were estimated to be EUR 1655 with semaglutide $0.5 \mathrm{mg}$, EUR 1425 with semaglutide $1 \mathrm{mg}$, and EUR 1680 with dulaglutide $1.5 \mathrm{mg}$. For the composite endpoint of HbA1c $<7.0 \%$ without hypoglycemia and without weight gain, semaglutide $0.5 \mathrm{mg}$, semaglutide $1 \mathrm{mg}$, and dulaglutide $1.5 \mathrm{mg}$ were associated with costs of control of EUR 1759, EUR 1521, and EUR 1941, respectively. Costs of control for the composite endpoint of $\geq 1.0 \%$ reduction in $\mathrm{HbA1c}$ with $\geq 5.0 \%$ weight loss were estimated to be EUR 2962, EUR 1908, and EUR 4894 for semaglutide $0.5 \mathrm{mg}$, semaglutide $1 \mathrm{mg}$, and dulaglutide $1.5 \mathrm{mg}$, respectively. Evaluation of relative cost of control showed that semaglutide was associated with a better efficacy-to-cost ratio versus dulaglutide for all three endpoints (Table 3).

\section{Sensitivity Analyses}

Sensitivity analyses, conducted around model inputs and assumptions, showed that the base case findings were robust to changes in these parameters, with cost of control results 
Table 3 Number of patients needed to treat to bring one patient to target and cost of control results relative to semaglutide $1 \mathrm{mg}$

\begin{tabular}{|c|c|c|c|c|}
\hline Endpoint & $\begin{array}{l}\text { Semaglutide } \\
0.5 \mathrm{mg}\end{array}$ & $\begin{array}{l}\text { Semaglutide } \\
1 \mathrm{mg}\end{array}$ & $\begin{array}{l}\text { Sitagliptin } \\
100 \mathrm{mg}\end{array}$ & $\begin{array}{l}\text { Dulaglutide } \\
1.5 \mathrm{mg}\end{array}$ \\
\hline \multicolumn{5}{|l|}{ Number need to treat } \\
\hline \multicolumn{5}{|l|}{ SUSTAIN 2} \\
\hline HbAlc $<7.0 \%$ & 1.45 & 1.28 & 2.78 & - \\
\hline $\begin{array}{l}\text { HbAlc }<7.0 \% \text { without hypoglycemia and } \\
\text { without weight gain }\end{array}$ & 1.59 & 1.35 & 3.70 & - \\
\hline $\begin{array}{l}\geq 1.0 \% \mathrm{HbAlc} \text { reduction with } \geq 5.0 \% \text { weight } \\
\text { loss }\end{array}$ & 2.86 & 1.85 & 11.11 & - \\
\hline \multicolumn{5}{|l|}{ SUSTAIN 7} \\
\hline $\mathrm{HbAlc}<7.0 \%$ & 1.47 & 1.27 & - & 1.49 \\
\hline $\begin{array}{l}\text { HbAlc }<7.0 \% \text { without hypoglycemia and } \\
\text { without weight gain }\end{array}$ & 1.56 & 1.35 & - & 1.72 \\
\hline $\begin{array}{l}\geq 1.0 \% \mathrm{HbAlc} \text { reduction with } \geq 5.0 \% \text { weight } \\
\text { loss }\end{array}$ & 2.63 & 1.69 & - & 4.35 \\
\hline \multicolumn{5}{|l|}{ Cost of control relative to semaglutide $1 \mathrm{mg}$} \\
\hline \multicolumn{5}{|l|}{ SUSTAIN 2} \\
\hline $\mathrm{HbAlc}<7.0 \%$ & 113 & 100 & 77 & - \\
\hline $\begin{array}{l}\text { HbAlc }<7.0 \% \text { without hypoglycemia and } \\
\text { without weight gain }\end{array}$ & 117 & 100 & 98 & - \\
\hline $\begin{array}{l}\geq 1.0 \% \mathrm{HbAlc} \text { reduction with } \geq 5.0 \% \text { weight } \\
\text { loss }\end{array}$ & 154 & 100 & 214 & - \\
\hline \multicolumn{5}{|l|}{ SUSTAIN 7} \\
\hline HbAlc $<7.0 \%$ & 116 & 100 & - & 118 \\
\hline $\begin{array}{l}\text { HbAlc }<7.0 \% \text { without hypoglycemia and } \\
\text { without weight gain }\end{array}$ & 116 & 100 & - & 128 \\
\hline $\begin{array}{l}\geq 1.0 \% \mathrm{HbAlc} \text { reduction with } \geq 5.0 \% \text { weight } \\
\text { loss }\end{array}$ & 155 & 100 & - & 257 \\
\hline
\end{tabular}

HbAlc glycated hemoglobin

remaining similar to the base case analyses in all scenarios (Table 4). Decreasing the proportions of patients achieving each endpoint by one standard error yielded higher cost of control values for all interventions. For SUSTAIN 2, cost of control was estimated to be EUR 1687, 1482, and 1196 for semaglutide $0.5 \mathrm{mg}$, semaglutide
$1 \mathrm{mg}$, and sitagliptin, respectively, for HbA1c $<7.0 \%$; EUR 1857, 1567, and 1622, respectively, for HbA1c $<7.0 \%$ without hypoglycemia and without weight gain; and EUR 3448, 2184, and 5305, respectively, for $\geq 1.0 \%$ reduction in $\mathrm{HbA} 1 \mathrm{c}$ with $\geq 5.0 \%$ weight loss. For SUSTAIN 7, semaglutide $0.5 \mathrm{mg}$, 


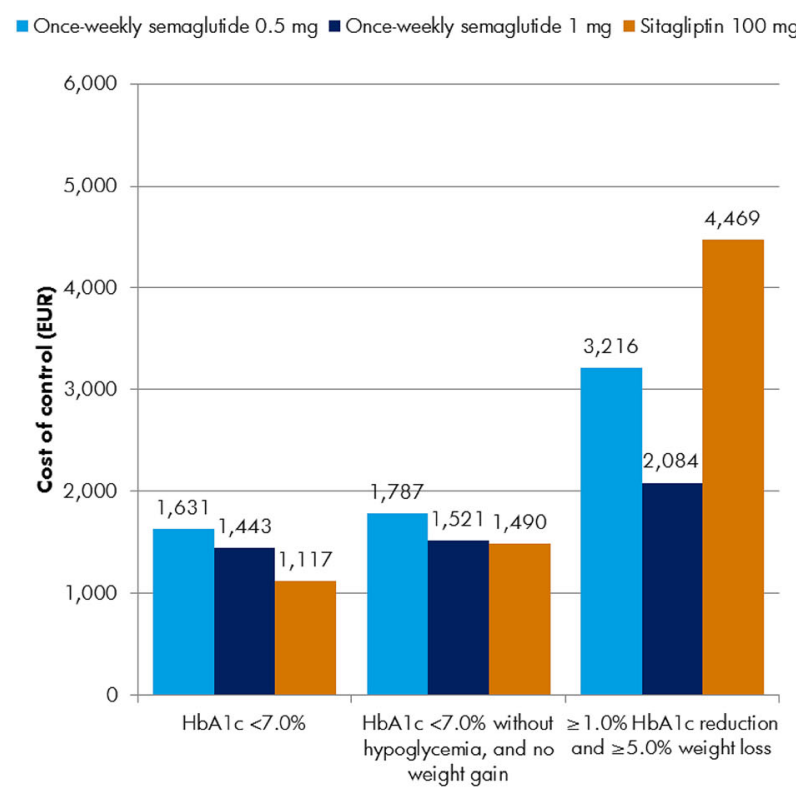

EUR, 2019 euros; HbA1c, glycated hemoglobin.

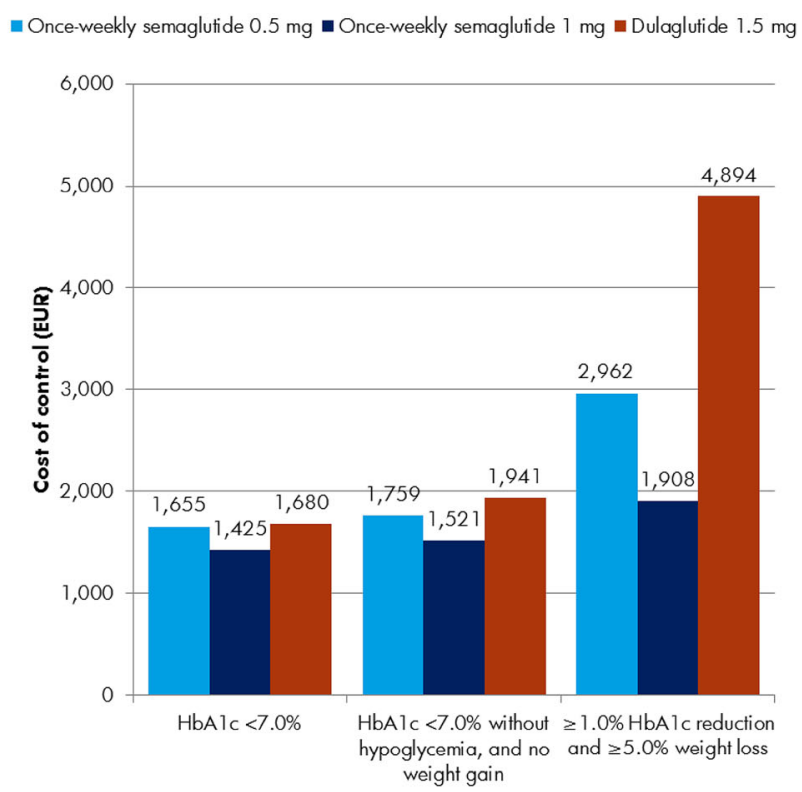

Fig. 1 Absolute cost of control based on SUSTAIN 2 and SUSTAIN 7. EUR 2019 euros, HbAlc glycated hemoglobin

semaglutide $1 \mathrm{mg}$, and dulaglutide $1.5 \mathrm{mg}$ were associated with cost of control values of EUR 1723, 1468, and 1751, respectively, for HbA1c $<7.0 \%$; EUR 1838, 1575, and 2041, respectively, for HbA1c $<7.0 \%$ without hypoglycemia and without weight gain; and EUR 3197, 2004, and 5473, respectively, for $\geq 1.0 \%$ reduction in $\mathrm{HbA} 1 \mathrm{c}$ with $\geq 5.0 \%$ weight loss.

Increasing the proportions of patients achieving each endpoint by one standard error led to the converse effect, with lower cost of control values for all interventions. For SUSTAIN 2, cost of control for reaching the endpoint of HbA1c $<7.0 \%$ was estimated to be EUR 1579, 1406, and 1048 for semaglutide $0.5 \mathrm{mg}$, semaglutide $1 \mathrm{mg}$, and sitagliptin, respectively; application of $\mathrm{HbA} 1 \mathrm{c}<7.0 \%$ without hypoglycemia and without weight gain yielded cost of control values of EUR 1721, 1478 , and 1377, respectively; and cost of control was estimated to be EUR 3013, 1993, and 3860 , respectively, for $\geq 1.0 \%$ reduction in HbA1c with $\geq 5.0 \%$ weight loss. For SUSTAIN 7, cost of control for semaglutide $0.5 \mathrm{mg}$, semaglutide $1 \mathrm{mg}$, and dulaglutide $1.5 \mathrm{mg}$ was estimated to be EUR 1592, 1384, and 1614, respectively, for $\mathrm{HbA1c}<7.0 \%$; EUR 1686, 1471 , and 1850, respectively, for HbA1c $<7.0 \%$ without hypoglycemia and without weight gain; and EUR 2759, 1820, and 4425, respectively, for $\geq 1.0 \%$ reduction in $\mathrm{HbA} 1 \mathrm{c}$ with $\geq 5.0 \%$ weight loss.

PSA, performed with sampling around the input data, resulted in comparable mean outcomes to the base case analysis (Table 4). Based on SUSTAIN 2, mean costs of control were EUR 1635, 1445, and 1123 for semaglutide $0.5 \mathrm{mg}$, semaglutide $1 \mathrm{mg}$, and sitagliptin, respectively, for a target of $\mathrm{HbA} 1 \mathrm{c}<7.0 \%$; EUR 1791, 1522, and 1495, respectively, for a target of HbA1c $<7.0 \%$ without hypoglycemia and without weight gain; and EUR 3217, 2088, and 4589 , respectively, for $\mathrm{a} \geq 1.0 \%$ reduction in $\mathrm{HbA1c}$ with $\geq 5.0 \%$ weight loss. Based on SUSTAIN 7, mean costs of control for semaglutide $0.5 \mathrm{mg}$, semaglutide $1 \mathrm{mg}$, and dulaglutide $1.5 \mathrm{mg}$ were EUR 1659, 1425, and 1683, respectively, for a target of $\mathrm{HbA} 1 \mathrm{c}<7.0 \%$; EUR 1764, 1523, and 1945, respectively, for a target of HbA1c $<7.0 \%$ without hypoglycemia and without weight gain; and EUR 2980, 1913, and 4967 , respectively, for $\mathrm{a} \geq 1.0 \%$ reduction in $\mathrm{HbA} 1 \mathrm{c}$ with $\geq 5.0 \%$ weight loss. 
Table 4 Sensitivity analysis results

\begin{tabular}{|c|c|c|c|c|c|c|}
\hline \multirow[t]{2}{*}{ Analysis } & \multicolumn{3}{|c|}{ Costs of control for SUSTAIN 2 (EUR) } & \multicolumn{3}{|c|}{ Costs of control for SUSTAIN 7 (EUR) } \\
\hline & $\begin{array}{l}\text { Semaglutide } \\
0.5 \mathrm{mg}\end{array}$ & $\begin{array}{l}\text { Semaglutide } \\
1 \mathrm{mg}\end{array}$ & $\begin{array}{l}\text { Sitagliptin } \\
100 \mathrm{mg}\end{array}$ & $\begin{array}{l}\text { Semaglutide } \\
0.5 \mathrm{mg}\end{array}$ & $\begin{array}{l}\text { Semaglutide } \\
1 \mathrm{mg}\end{array}$ & $\begin{array}{l}\text { Dulaglutide } \\
1.5 \mathrm{mg}\end{array}$ \\
\hline \multicolumn{7}{|l|}{$\mathrm{HbA} 1 \mathrm{c}<7.0 \%$} \\
\hline Base case & 1631 & 1443 & 1117 & 1655 & 1425 & 1680 \\
\hline $\begin{array}{l}\text { Proportion of patients } \\
\text { reaching target minus one } \\
\text { standard error }\end{array}$ & 1687 & 1482 & 1196 & 1723 & 1468 & 1751 \\
\hline $\begin{array}{l}\text { Proportion of patients } \\
\text { reaching target plus one } \\
\text { standard error }\end{array}$ & 1579 & 1406 & 1048 & 1592 & 1384 & 1614 \\
\hline PSA & 1635 & 1445 & 1123 & 1659 & 1425 & 1683 \\
\hline \multicolumn{7}{|c|}{ HbAlc $<7.0 \%$ without hypoglycemia and without weight gain } \\
\hline Base case & 1787 & 1521 & 1490 & 1759 & 1521 & 1941 \\
\hline $\begin{array}{l}\text { Proportion of patients } \\
\text { reaching target minus one } \\
\text { standard error }\end{array}$ & 1857 & 1567 & 1622 & 1838 & 1575 & 2041 \\
\hline $\begin{array}{l}\text { Proportion of patients } \\
\text { reaching target plus one } \\
\text { standard error }\end{array}$ & 1721 & 1478 & 1377 & 1686 & 1471 & 1850 \\
\hline PSA & 1791 & 1522 & 1495 & 1764 & 1523 & 1945 \\
\hline \multicolumn{7}{|c|}{$\geq 1.0 \% \mathrm{HbA} 1 \mathrm{c}$ reduction with $\geq 5.0 \%$ weight loss } \\
\hline Base case & 3216 & 2084 & 4469 & 2962 & 1908 & 4894 \\
\hline $\begin{array}{l}\text { Proportion of patients } \\
\text { reaching target minus one } \\
\text { standard error }\end{array}$ & 3448 & 2184 & 5305 & 3197 & 2004 & 5473 \\
\hline $\begin{array}{l}\text { Proportion of patients } \\
\text { reaching target plus one } \\
\text { standard error }\end{array}$ & 3013 & 1993 & 3860 & 2759 & 1820 & 4425 \\
\hline PSA & 3217 & 2088 & 4589 & 2980 & 1913 & 4967 \\
\hline
\end{tabular}

EUR 2019 euros, HbAlc glycated hemoglobin, PSA probabilistic sensitivity analysis

\section{DISCUSSION}

The present analysis indicated that costs of control were highly dependent on the desired treatment target. Based on data from SUSTAIN 2, sitagliptin was associated with a lower cost of control when considering only glycemic control (HbA1c $<7.0 \%$ ), but modern treatment targets for type 2 diabetes often incorporate additional clinically relevant parameters, as these have been shown to also reduce the risk of long-term complications 
[10-12]. When these factors were considered in the endpoint of $\mathrm{HbA} 1 \mathrm{c}<7.0 \%$ without hypoglycemia and without weight gain, semaglutide $1 \mathrm{mg}$ and sitagliptin were associated with comparable costs of control, while combination of these factors in the endpoint of $\geq 1.0 \%$ reduction in $\mathrm{HbA} 1 \mathrm{c}$ with $\geq 5.0 \%$ weight loss led to both doses of semaglutide being associated with lower costs of control versus sitagliptin. Based on data from SUSTAIN 7, semaglutide yielded the lowest cost of control values for all three endpoints versus dulaglutide $1.5 \mathrm{mg}$. These short-term efficacy benefits are likely to confer long-term benefits in terms of fewer diabetesrelated complications, as shown throughout the published literature [6-12]. These results also correlate with the latest EASD guidelines, which indicate semaglutide as the preferred GLP-1 receptor agonist in patients seeking to avoid weight gain [5]. The interventions included in this analysis differ in terms of glucose-lowering potential. The increased efficacy of semaglutide, particularly the $1 \mathrm{mg}$ dose, compared with sitagliptin and dulaglutide $1.5 \mathrm{mg}$ was the key driver of lower cost of control outcomes in the present analysis.

The captured costs, time horizon, and perspective should be considered when interpreting the findings of the present analysis. Only medication acquisition costs were included in the analysis-the costs of diabetes-related complications were not included, as these would not be expected to differ over the 1-year time horizon, and neither micro- nor macrovascular complications were assessed in SUSTAIN 2 or SUSTAIN 7. Moreover, the proportions of patients achieving the included endpoints from the two trials were taken from different time periods (56 weeks for SUSTAIN 2 and 40 weeks for SUSTAIN 7) and this should be considered when comparing the two sets of results, especially given the combination of these clinical data with annual treatment costs. However, intra-trial comparisons of semaglutide and the comparator used clinical data collected at the same time point, meaning any drawbacks of this approach should be equally prevalent in both treatment arms for these comparisons. Additionally, the present analysis is designed to complement, not replace, conventional long- term analyses, and demonstration of the shortterm benefits of an intervention with clinically relevant endpoints offers additional pertinent information for healthcare payers considering short-term budgets. The approach used in the present analysis has also been previously demonstrated throughout the published literature $[28,32,33]$. Furthermore, how well the randomized controlled trial cohorts reflect the Spanish population with type 2 diabetes also needs to be considered. The SUSTAIN 2 and SUSTAIN 7 trials enrolled $6 \%$ and $5 \%$ of the total study participants in Spain. The patients enrolled in Spain were similar to those enrolled in other countries, and therefore it is likely that the clinical trials used to inform the present analysis are representative of the appropriate population in Spain.

To date, there is no evidence to inform indirect costs, such as lost workplace productivity, associated with semaglutide, sitagliptin, and dulaglutide in Spain. Therefore these costs were not included in the present analysis. As these costs become available, future analyses should look to capture these costs.

A further limitation was the threshold-based binary classifiers of glycemic control in both the single and composite endpoints. Whilst the threshold of $7 \%$ was based on the current EASD treatment guidelines and is therefore clinically relevant, glycemic control improvements observed in patients not reaching target (or not meeting or exceeding a $1.0 \%$ reduction) were not captured in the analysis. However, given the larger proportions of patients reaching target with semaglutide, and the lower HbA1c levels achieved relative to the other agents, this assumption is likely to be conservative from the semaglutide perspective [18-21].

Short-term analyses also offer several advantages over their long-term counterparts, primarily in their simplicity, transparency, and ease of interpretation, with outcomes that are easily explainable to both patients and healthcare professionals. Moreover, these analyses can be easily updated if new clinical data become available, or if medication prices change, and no long-term projections of short-term data are required (in contrast to typical long-term 
diabetes modeling) avoiding the uncertainty associated with data extrapolation.

\section{CONCLUSIONS}

Based on data from SUSTAIN 2, sitagliptin was associated with a lower cost of control when considering solely glycemic control, but semaglutide $1 \mathrm{mg}$ was associated with comparable or lower costs of control versus sitagliptin when considering composite endpoints incorporating avoidance of hypoglycemia and weight loss alongside glycemic control, and semaglutide $0.5 \mathrm{mg}$ was associated with lower costs of control when considering the endpoint of $\geq 1.0 \%$ reduction in $\mathrm{HbA1c}$ with $\geq 5.0 \%$ weight loss. Based on data from SUSTAIN 7, semaglutide $0.5 \mathrm{mg}$ and $1 \mathrm{mg}$ were associated with lower costs of control compared with dulaglutide for both single endpoints capturing glycemic control and composite endpoints incorporating hypoglycemia risk and weight loss in Spain.

\section{ACKNOWLEDGEMENTS}

Funding. The present cost-effectiveness analysis and the Rapid Service Fee were supported by funding from Novo Nordisk A/S.

Authorship. All named authors meet the International Committee of Medical Journal Editors (ICMJE) criteria for authorship for this article, take responsibility for the integrity of the work as a whole, and have given their approval for this version to be published.

Authorship Contributions. The study was designed by all authors, and conducted by Barnaby Hunt and Virginia Martin. The manuscript was drafted by Samuel Malkin, and revised by Josep Vidal, Barnaby Hunt, Virginia Martín, Nino Hallén, and Francisco Javier Ortega. All authors had full access to all of the data in this study, take responsibility for the integrity of the work as a whole, and have given approval for the final version to be published.
Disclosures. Josep Vidal has the following financial relationships: advisor on scientific boards for Novo Nordisk and lectures for Eli Lilly and Company, Merck Sharp \& Dohme and Novo Nordisk. Javier Ortega declares to receive honoraria for lectures, conferences and publications of: Abbot Laboratories, Almirall, AstraZeneca, Bayer, Biohorm, Boehringer Ingelheim, Bristol-Myers Squibb, Chiesi, Eli Lilly and Company, Esteve, Ferrer, GlaxoSmithKline, Grupo Menarini, Grupo Uriach, Janssen Pharmaceuticals, Merck Sharp \& Dohme, Mylan, Novartis, Novo Nordisk, Sandoz, Sanofi Aventis, Schering-Plough and Servier. Samuel Malkin and Barnaby Hunt are employees of Ossian Health Economics and Communications, which received consulting fees from Novo Nordisk A/S to support preparation of the analysis. Virginia Martín is an employee of Novo Nordisk Pharma SA. Nino Hallén is an employee of Novo Nordisk $\mathrm{A} / \mathrm{S}$.

Compliance with Ethics Guidelines. This article is based on previously conducted studies and does not contain any studies with human participants or animals performed by any of the authors.

Data Availability. All data generated or analyzed during this study are included in this published article.

Open Access. This article is distributed under the terms of the Creative Commons Attribution-NonCommercial 4.0 International License (http://creativecommons.org/licenses/ by-nc/4.0/), which permits any noncommercial use, distribution, and reproduction in any medium, provided you give appropriate credit to the original author(s) and the source, provide a link to the Creative Commons license, and indicate if changes were made.

\section{REFERENCES}

1. International Diabetes Federation. Diabetes Atlas8th edition. 2017. http://www.diabetesatlas.org/ across-the-globe.html. Accessed April 08, 2019. 
2. International Diabetes Federation. IDF Europe Members-Spain. 2019. https://www.idf.org/ournetwork/regions-members/europe/members/159spain.html. Accessed April 08, 2019.

3. Lopez-Bastida J, Boronat M, Moreno JO, Schurer W. Costs, outcomes and challenges for diabetes care in Spain. Glob Health. 2013;9:17.

4. Working group of the Clinical Practice Guideline for type 2 Diabetes. Clinical Practice Guideline on type 2 Diabetes [Internet]. Madrid: National Plan for the NHS of the MSC. Health Technologies Assessment Agency of the Basque Country; 2008. Clinical Practice Guidelines in the Spanish NHS: OSTEBA No. 2006/08. http://www.guiasalud.es/ egpc/traduccion/ingles/diabetes/completa/index. html. Accessed April 08, 2019.

5. Davies MJ, D’Alessio DA, Fradkin J, et al. Management of hyperglycemia in type 2 diabetes, 2018. A Consensus Report by the American Diabetes Association (ADA) and the European Association for the Study of Diabetes (EASD). Diabetes Care. 2018;41(12):2669-701.

6. Ismail-Beigi F, Craven T, Banerji MA, et al. Effect of intensive treatment of hyperglycaemia on microvascular outcomes in type 2 diabetes: an analysis of the ACCORD randomised trial. Lancet. 2010;376:419-30.

7. Patel A, MacMahon S, Chalmers J, et al. Intensive blood glucose control and vascular outcomes in patients with type 2 diabetes. $\mathrm{N}$ Engl J Med. 2008;358:2560-72.

8. Stettler C, Allemann S, Jüni P, et al. Glycemic control and macrovascular disease in types 1 and 2 diabetes mellitus: meta-analysis of randomized trials. Am Heart J. 2006;152(1):27-38.

9. Holman RR, Paul SK, Bethel MA, Matthews DR, Neil HA. 10-year follow-up of intensive glucose control in type 2 diabetes. N Engl J Med. 2008;359:1577-89.

10. UK Prospective Diabetes Study (UKPDS) Group. Intensive blood-glucose control with sulphonylureas or insulin compared with conventional treatment and risk of complications in patients with type 2 diabetes (UKPDS 33). Lancet. 1998;352: 837-53.

11. Gaede P, Lund-Andersen H, Parving HH, Pedersen $O$. Effect of a multifactorial intervention on mortality in type 2 diabetes. N Engl J Med. 2008;358: 580-91.

12. Griffin SJ, Borch-Johnsen K, Davies MJ, et al. Effect of early intensive multifactorial therapy on 5-year cardiovascular outcomes in individuals with type 2 diabetes detected by screening (ADDITION-
Europe): a cluster-randomised trial. Lancet. 2011;378(9786):156-67.

13. Aschner P, Kipnes MS, Lunceford JK, et al. Effect of the dipeptidyl peptidase- 4 inhibitor sitagliptin as monotherapy on glycemic control in patients with type 2 diabetes. Diabetes Care. 2006;29(12):2632-7.

14. Russell-Jones D, Vaag A, Schmitz O, et al. Liraglutide vs insulin glargine and placebo in combination with metformin and sulfonylurea therapy in type 2 diabetes mellitus (LEAD-5 met $+\mathrm{SU}$ ): a randomised controlled trial. Diabetologia. 2009;52(10): 2046-55.

15. Anderson SL, Trujillo JM. Basal insulin use with GLP-1 receptor agonists. Diabetes Spectr. 2016;29(3):152-60.

16. Nauck M, Weinstock RS, Umpierrez GE, Guerci B, Skrivanek Z, Milicevic Z. Efficacy and safety of dulaglutide versus sitagliptin after 52 weeks in type 2 diabetes in a randomized controlled trial (AWARD-5). Diabetes Care. 2014;37(8):2149-58.

17. Tuttle KR, Lakshmanan MC, Rayner B, et al. Dulaglutide versus insulin glargine in patients with type 2 diabetes and moderate-to-severe chronic kidney disease (AWARD-7): a multicentre, open-label, randomised trial. Lancet Diabetes Endocrinol. 2018;6(8):605-17.

18. Ahrén B, Masmiquel L, Kumar H, et al. Efficacy and safety of semaglutide versus once-daily sitagliptin as an add-on to metformin, thiazolidinediones, or both, in patients with type 2 diabetes (SUSTAIN 2): a 56-week, double-blind, phase 3a, randomised trial. Lancet Diabetes Endocrinol. 2017;5(5): 341-54.

19. Ahmann AJ, Capehorn M, Charpentier G, et al. Efficacy and safety of semaglutide versus exenatide ER in subjects with type 2 diabetes (SUSTAIN 3): a 56-week, open-label, randomized clinical trial. Diabetes Care. 2018;41(2):258-66.

20. Aroda VR, Bain SC, Cariou B, et al. Efficacy and safety of semaglutide versus once-daily insulin glargine as add-on to metformin (with or without sulfonylureas) in insulin-naive patients with type 2 diabetes (SUSTAIN 4): a randomised, open-label, parallel-group, multicentre, multinational, phase 3a trial. Lancet Diabetes Endocrinol. 2017;5(5): 355-66.

21. Pratley RE, Aroda VR, Lingvay I, et al. Semaglutide versus dulaglutide once weekly in patients with type 2 diabetes (SUSTAIN 7): a randomised, openlabel, phase $3 \mathrm{~b}$ trial. Lancet Diabetes Endocrinol. 2018;6(4):275-86. 
22. Witkowski M, Wilkinson L, Webb N, Weids A, Glah $D$, Vrazic H. A systematic literature review and network meta-analysis comparing semaglutide with other GLP-1 receptor agonists in patients with type 2 diabetes previously receiving 1-2 oral antidiabetic drugs. Diabetes Ther. 2018;9(3):1149-67.

23. Sharma R, Wilkinson L, Vrazic H, et al. Comparative efficacy of semaglutide and SGLT-2 inhibitors in type 2 diabetic patients inadequately controlled with metformin monotherapy: a systematic literature review and network meta-analysis. Curr Med Res Opin. 2018;34(9):1595-603.

24. Marso SP, Bain SC, Consoli A, et al. Semaglutide and cardiovascular outcomes in patients with type 2 diabetes. $N$ Engl J Med. 2016;375(19): 1834-44.

25. Marso SP, Daniels GH, Brown-Frandsen K, et al. Liraglutide and cardiovascular outcomes in type 2 diabetes. N Engl J Med. 2016;375:311-22.

26. Gerstein HC, Colhoun HM, Dagenais GR, et al. Dulaglutide and cardiovascular outcomes in type 2 diabetes (REWIND): a double-blind, randomised placebo-controlled trial. Lancet. 2019;394(10193): 121-30.

27. Green JB, Bethel MA, Armstrong PW, et al. Effect of sitagliptin on cardiovascular outcomes in type 2 diabetes. N Engl J Med. 2015;373:232-42.

28. Wilkinson L, Hunt B, Johansen P, Iyer NN, DangTan T, Pollock RF. Cost of achieving HbA1c treatment targets and weight loss responses with semaglutide versus dulaglutide in the United States. Diabetes Ther. 2018;9(3):951-61.

29. European Medicines Agency. Trulicity. http://www. ema.europa.eu/ema/index.jsp?curl=pages/medicin es/human/medicines/002825/human_med_0018 21.jsp\&mid=WCOb01ac058001d124. Accessed June 01, 2018.

30. Rodbard HW, Bellary S, Hramiak I, et al. Greater combined reductions in $\mathrm{HbA} 1 \mathrm{c} \geq 1.0 \%$ and weight $\geq 5.0 \%$ with semaglutide versus comparators in type 2 diabetes. Endocr Pract. 2019;25(6):589-97.

31. Nomenclátor de facturación [Billing nomenclature]. Ministerio de Sanidad, Consumo y Bienestar Social [Ministry of Health, Consumption and Social Welfare]. https://www.mscbs.gob.es/profesionales/ nomenclator.do. Accessed July 01, 2019.

32. Billings LK, Mocarski M, Basse A, Hunt B, Valentine WJ, Jodar E. Cost of achieving HbA1c and weight loss treatment targets with IDegLira vs insulin glargine U100 plus insulin aspart in the USA. Clinicoecon Outcomes Res. 2019;11:271-82.

33. Skovgaard R, Jon Ploug U, Hunt B, Valentine WJ. Evaluating the cost of bringing people with type 2 diabetes mellitus to multiple targets of treatment in Canada. Clin Ther. 2015;37(8):1677-88. 